\title{
57. INTRODUCTION TO THE GUAYMAS SLOPE AND LAMINATED DIATOMITE SYMPOSIUM1
}

\author{
Joseph R. Curray and David G. Moore, Scripps Institution of Oceanography, La Jolla, California
}

This collection of papers represents the third and final of our regional/topical research endeavors on DSDP Leg 64-namely, drilling of the sites on the northeastern slope of the Guaymas Basin. Three scientific objectives led to the selection of these sites: first, to attempt to determine the nature of the proto-Gulf of California, and the mechanism of its earlier stage of opening; second, to elucidate the tectonic history of the Guaymas Basin region, as revealed in unconformities in the sedimentary section; and third, to sample the laminated diatomaceous sediments known previously from oceanographic ship piston cores. A fourth technological objective was to test the newly developed DSDP Serocki-Storms-Cameron hydraulic piston corer (HPC).

Earlier sampling and studies of seismic-reflection records from the Gulf of California have demonstrated that an extensive marine embayment antedated the present 3.5-m.y. phase of opening of the Gulf of California. This "proto-Gulf" may have had deep basins as far north as Guaymas, and was an epicontinental sea farther to the north. A considerable thickness of marine sediments had accumulated in the presumed "protoGulf," both in the southern basins and in the shallow sea that extended far to the north and east of the present Gulf. This proto-Gulf was thought to have existed at least by Miocene time, but little was known of the time of formation or nature of the crust underlying the proto-Gulf sedimentary section. Thickness of this sedimentary section and safety considerations precluded the possibility of penetrating to proto-Gulf basement, but our plan was to learn as much as possible about the nature and age of the sedimentary section. Furthermore, earlier seismic studies had revealed an intricate system of unconformities, offering the possibility of yielding information on rather recent tectonic history. Our subsequent analysis of the drilling and other geophysical and geological data have, however, led us to the concept of a single process of opening, with a proto-Gulf phase and a post-3.5 m.y. phase (Moore and Curray, this volume, Pt. 2).

Many earlier studies of oceanography and sedimentology in the Gulf of California had shown the existence of laminated diatomaceous sediments, where the oxygen minimum impinges on the continental slope in the central Gulf. These sites were located in the region where previous piston cores had insured a good probability of encountering such laminated sediments. The previous

\footnotetext{
${ }^{1}$ Curray, J. R., Moore, D. G., et al,, Init. Repts. DSDP, 64: Washington (U.S. Govt. Printing Office).
}

studies of these laminated sediments has suggested that the couplets are annual varves and are related to variations in diatom productivity and/or influx of terrigenous sediment. Sampling of these varved sediments therefore offered the possibility of yielding considerable information on Quaternary climatic and oceanographic conditions and variations.

Site 479, our first hole in this region (Figs. 1 and 2,), was placed within the area of known varved diatomaceous sediments and in the axis of a syncline, where penetration of the sedimentary section presented the fewest hazards of hydrocarbon accumulation. Recovery in the upper soft sediment part of the section was disappointing, and the shipboard sedimentologists could not determine with confidence whether the upper disturbed cores were indeed well laminated. Furthermore, encountering of potentially hazardous quantities and increasingly maturated kinds of hydrocarbons forced termination of the drilling short of our pre-determined objectives. Nevertheless, considerable information on ages of the unconformities was gained.

At the midpoint of Leg 64, while on Site 477 and during the transfer of personnel on and off Glomar Challenger, the newly developed prototype model of the DSDP Serocki-Storms-Cameron hydraulic piston corer was loaded aboard the ship. A preliminary attempt to use this new tool was made during drilling of Hole 477A, but without success. Our Laboratory Officer, Donald Cameron, one of the engineers who developed this new tool, effected some modifications in the corer and in handling procedures before occupying Site 480 . Inasmuch as our experience on 477 could not confirm the existence of laminated sediments in the shallow sedimentary section, we moved a few kilometers before occupying Site 480 . At that new site, at 15 minutes after midnight on New Year's Day, 1979, the first successful hydraulic piston core was brought aboard Glomar Challenger, displaying beautifully preserved, undisturbed, laminated, diatomaceous sediments. Our success continued, almost without loss or failure, through the next day for a total of 33 cores and recovery of most of 150 meters of alternately varved and homogeneous sedimentary section. The shipboard scientists, realizing the unusual value and potential of these cores, elected to do no sampling other than surface scraping from the split halves of the cores, thus preserving these valuable varved sedimentary cores for more careful sampling back at DSDP in La Jolla. This delayed most studies considerably. The papers presented in this symposium thus are only preliminary results of what promises to be many years of continuing study of this unique set of cores. 


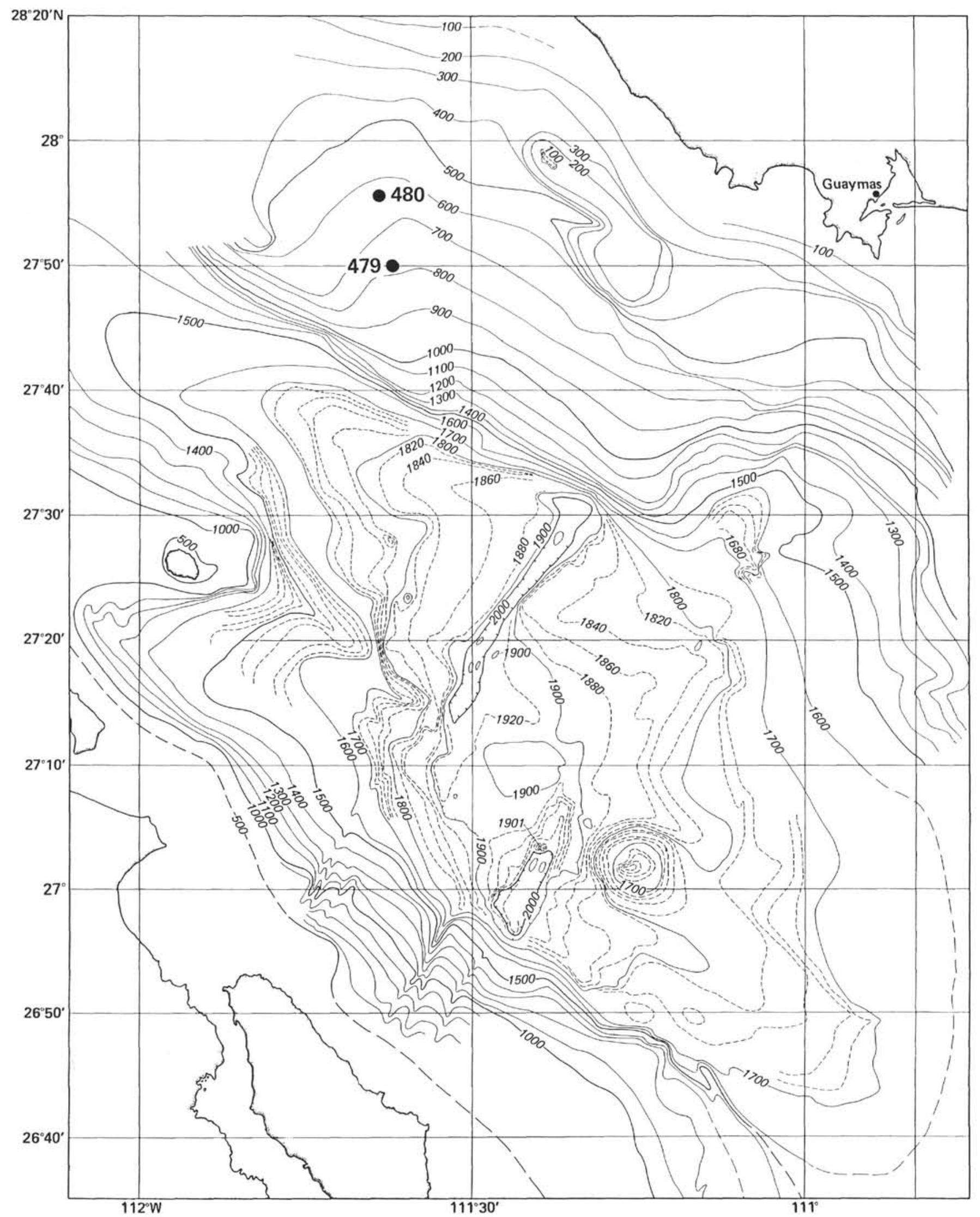

Figure 1. Bathymetry of the Guaymas Basin (modified from Sharman, 1976, by F. J. Emmel and H. E. Sheline). 


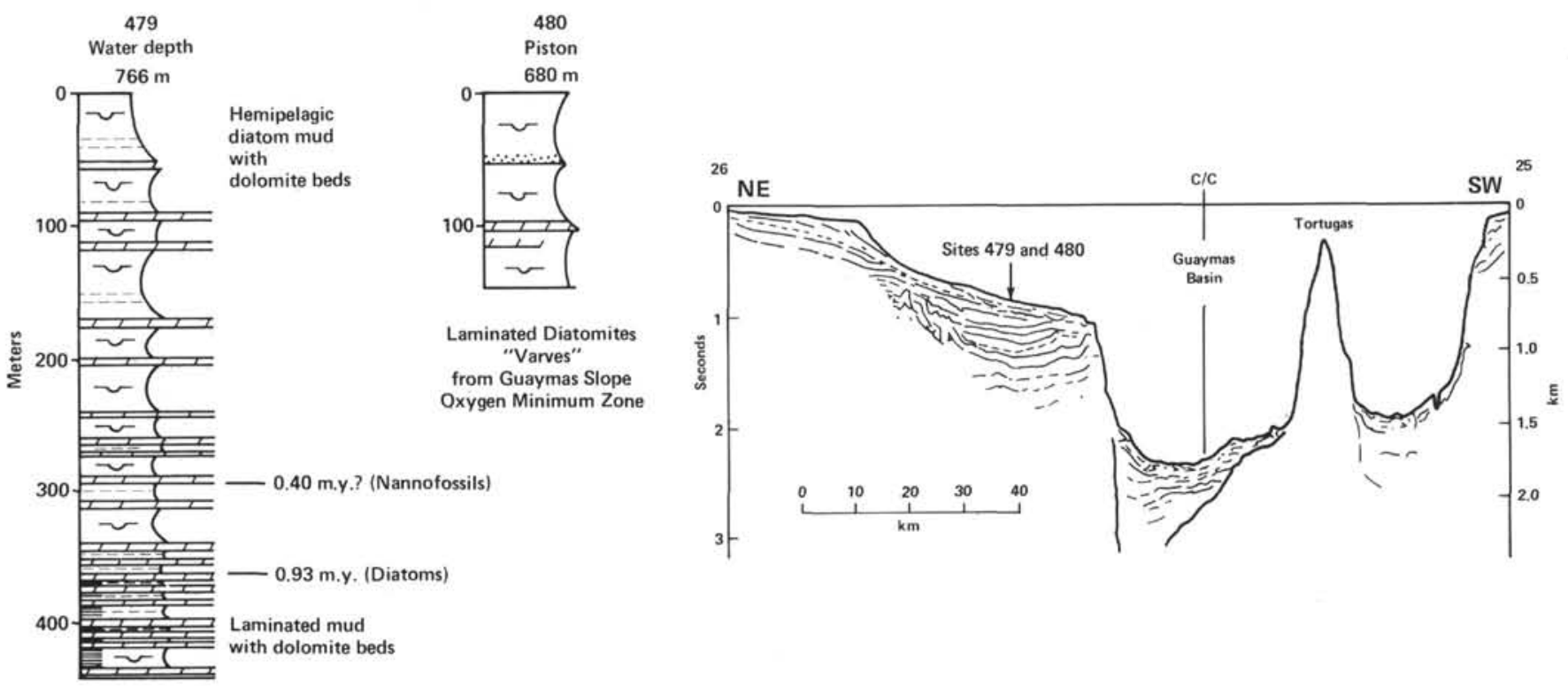

Figure 2. Simplified principal lithologic results and line drawing of seismic section through Sites 479 and 480 . 